\title{
Out of hours ophthalmic surgery: a UK national survey
}

U O'Colmain'1, M Wright'², H Bennett ${ }^{2}$ and

CJ MacEwen'

\begin{abstract}
Aims There have been significant changes in the management of out of hours services in ophthalmology recently. The European Working Time Directive (EWTD) and economic measures have anecdotally reduced the availability of staff and facilities outside normal working hours, and there have been various responses to the provision of emergency surgical care. There are disparate attitudes to the optimum management of the emergency surgical case. We sought to establish a nationwide picture of the management of out of hours surgery.

Methods A questionnaire was distributed to every consultant ophthalmologist working in the NHS and registered with the Royal College of Ophthalmologists $(n=947)$. Information was requested regarding departmental and personal policies, local facilities, and personal beliefs regarding emergency surgery.
\end{abstract}

Results A total of 440 (46.5\%) questionnaires were returned from 155 units; $18.7 \%$ of the units had no out of hours services or no operating facilities. Sixty-three percent of units reported a local policy regarding a time after which patients should not be taken to theatre. For $57 \%$, this time began between 2100 hours and midnight. The most common reasons for not operating after a certain time were 'belief that delay does not significantly affect the outcome' (41.6\%), 'delayed access to theatre due to competition with other surgical specialities' (40\%), and 'no specialist ophthalmic-theatre nursing input' $(32.7 \%)$. Conclusion We report the first nationwide study on out of hours ophthalmological surgical working practices. This demonstrates variation in work patterns. It is significant to patients and ophthalmologists that there should be units in United Kingdom without full local facilities and staff. Eye (2013) 27, 363-366; doi:10.1038/ eye.2012.280; published online 1 February 2013

Keywords: after-hours care; ophthalmologic surgical procedures; policy; training

\section{Introduction}

Recent years have seen significant changes in the management of all out of hours medical services, including ophthalmology. Alteration to training structures with Modernising Medical Careers (MMC), the European Working Time Directive (EWTD), incremental subspecialisation, and economic measures have resulted in changes to the way all services are administered and delivered; staff and facilities are now not universally available due to the loss of traditional hospital team structures, shortened training times, and the economic unsustainability of full service provision in smaller regional hospitals. It is common for units to have reciprocal arrangements for out of hours cover that results in patients travelling to neighbouring units for emergency care; although in some cases the arrangement may not be reciprocal. Frequently, trainee and consultant ophthalmologists travel to different units to provide this care. This is an evolving infrastructure and there are little published data describing the current situation.

Additionally, there are many different attitudes to the optimum management of the emergency surgical case. Recommendations and guidelines are published by the National

Confidential Enquiry into Patient Outcomes and Death (NCEPOD) ${ }^{1}$ and the Royal College of Ophthalmologists. ${ }^{2}$

We sought to establish a nationwide picture of the management of out of hours ophthalmic emergency surgery. The purpose of this study was to assemble data regarding current out of hours surgical practices in ophthalmology units in United Kingdom.

\section{Methods}

A questionnaire was distributed by post to every consultant ophthalmologist working in the NHS and registered with the Royal College of Ophthalmologists $(n=947)$. Information was
${ }^{1}$ Department of Ophthalmology, Ninewells Hospital and Medical School, Dundee, UK

${ }^{2}$ Department of Ophthalmology, The Princess Alexandra Eye Pavilion, Edinburgh, UK

Correspondence:

U O'Colmain, Department of Ophthalmology, Ninewells Hospital and Medical School, Ninewells Avenue, Dundee DD1 9SY, UK.

Tel: +44 (0)1382 660111;

Fax: +44 (0)1382 632893

E-mail: uocolmain@nhs.net

Received: 18 November 2011

Accepted: 11 April 2012 Published online: 1 February 2013

Presented as a poster at the Oxford Ophthalmological Congress, July 2011. 
sought using close-ended questions on departmental and personal policies for taking patients to theatre for an ophthalmic emergency requiring surgical intervention (Figure 1). The reasons for these decisions were requested using open-ended questions with some options provided. Consultants were asked to give as many reasons and comments as they felt pertinent. The results were grouped by units and examined individually where appropriate. Prior to distribution, the questionnaire was trialled by several consultants from two different units; the questionnaire was refined on the basis of this pilot and distributed nationwide.

\section{Results}

A total of 440 questionnaires were returned from 155 different units. Twenty-four units (15.5\%) reported they had no out of hours services or sent all out of hours emergencies to another unit. A further 5 units (3.2\%) stated that they do out of hours work, but only have access to general operating theatres with no suitable equipment or microscope.

One-hundred units $(64.5 \%)$ reported that they had a departmental policy regarding a time limit beyond which they could no longer take a case to theatre out of hours.

\section{Ophthalmology Out of Hours Surgical Practice - Questionnaire}

1) Is there a specified time in your unit beyond which you would not take a patient to theatre for an ophthalmic injury that requires surgical intervention (e.g. globe rupture, laceration) but would defer until the next elective list?

$$
\text { Yes } \square \quad \text { No } \square
$$

2) If yes, what is the 'evening' deadline?

3) If you do not have a specified time, do you personally have a time limit for
taking a patient to surgery?
What is that time?
4) Why have you reached these decisions? For example:
i) No specialist ophthalmic theatre nursing input
ii) Delayed access to emergency theatre time because of 'low surgical
iii) Belief that delayed repair does not significantly affect the outcome
iv) Awareness of tomorrow's elective work

Please give as many reasons or comments as you feel are pertinent

Email address for results:

Figure 1 Postal questionnaire sent to consultant ophthalmologists.
The median time was $21 \mathrm{~h}$, range 16-24 h (Figure 2). Fiftyfive units $(35.5 \%)$ reported that they did not have a departmental policy regarding a time limit beyond which they could not take a case to theatre.

Eighty-nine units $(57.4 \%)$ reported they had no access to specialist ophthalmic nursing support or to specialist theatre facilities for their out of hours activities.

The reasons given for choosing a time limit for taking a patient to theatre out of hours were: (1) belief that delay does not significantly affect the outcome (41.6\%), (2) delayed access to theatre (40\%), (3) no specialist ophthalmic nursing input $(32.7 \%)$, (4) awareness of elective caseload the next day (25\%), (5) concern regarding levels of fatigue $(12.5 \%)$, (6) better quality of staff, work, and equipment during the day $(9.3 \%)$, (7) anaesthetic unavailability (4.5\%), (8) unavailability of specialist ophthalmic-theatre equipment $(4.1 \%)$, (9) NCEPOD recommendations (2.5\%), and (10) RCOphth guidelines (0.5\%) (Figure 3).

Fourty-three consultants specifically added a comment to state that they dealt with each case on its individual merits and did not, therefore, hold a general policy. Eight consultants indicated that they treat endophthalmitis as an exceptional case, and 14 consultants specified that they would treat a child as an exceptional case.

Seventeen questionnaires were excluded because of the cessation of employment of that consultant owing to various reasons. Two were excluded as the source unit had been omitted.

Sixty-two consultants gave conflicting results to their departmental colleagues regarding their departmental policy on an out of hours time limit; in this situation the response with most consistency within the unit was used for this section.

\section{Discussion}

Our results describe the current attitudes and practices of consultant ophthalmologists and ophthalmic units in United Kingdom regarding out of hours surgery. There is

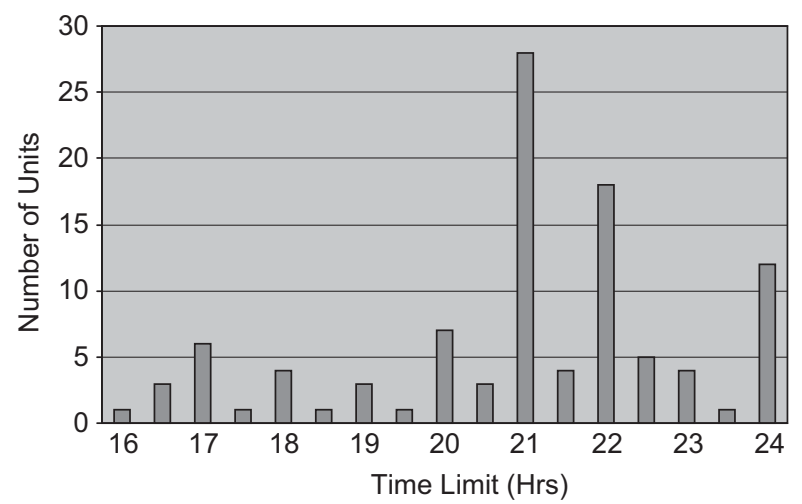

Figure 2 Department time limits for emergency ophthalmic surgery out of hours. 


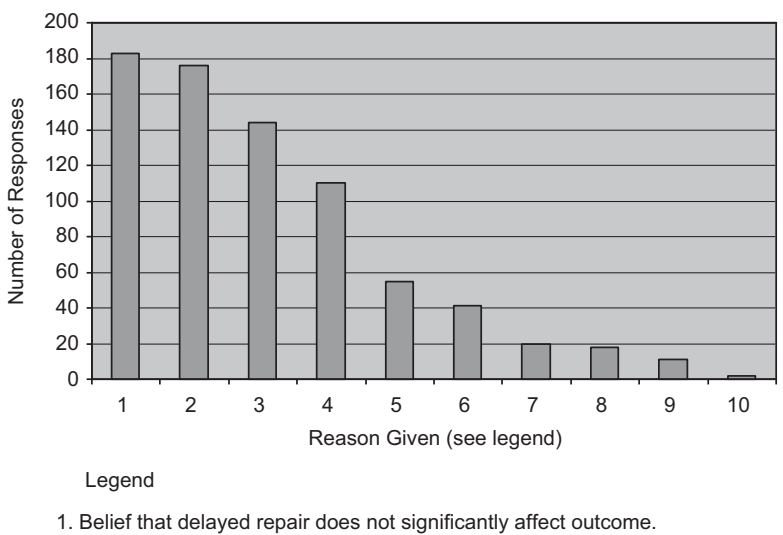

2. Delayed access to emergency theatre time due to 'low surgical priority' as perceived by the competing surgical specialities.

3. No specialist ophthalmic theatre nursing input.

4. Awareness of tomorrow's elective work.

5. Concern regarding levels of fatigue.

6. Reduced quality of surgical skills and environment.

7. Anaesthetic unavailability.

8. Unavailability of specialist ophthalmic theatre equipment.

9. NCEPOD recommendations.

10. RCOphth guidelines

Figure 3 Reasons given for a specified time limit.

no doubt that the hospital landscape is changing in relation to workforce numbers and structures, and it is likely that this will continue to evolve in the future. Although there exist useful guidelines for clinicians and hospital managers regarding out of hours care, there are few published data on practices around the country. A previous survey of surgical trainees published after the introduction of the 56-h-working week due to the EWTD described a decrease in training time, trainer contact, and surgical experience, ${ }^{3}$ we wanted to obtain factual evidence of local practices and protocols as well as opinions regarding best practice and the challenges encountered out of hours. The cases that are typically seen out of hours, which require surgical intervention, are challenging to manage, and decision making regarding management will require consultant involvement. ${ }^{1}$

To date, there are limited data on the optimal management of these cases as they are rare and varied; recent work on the management of open-globe injuries in military situations with a mean time to primary repair of 1.9 days had final visual acuities which correlated with the Ocular Trauma Score. 4,5 Better final outcomes were described for perforating globe injuries and intraocular foreign bodies that had delayed secondary repair or removal of foreign body, but these patients had undergone primary repair 'within hours' ${ }^{6,7}$ It is clear from our data that certain situations, such as pediatric trauma and endophthalmitis, may be treated as exceptional cases, and these will invariably make up a significant minority of out of hours presentations. It is reasonable to imagine that there should be scope in any system to allow for different approaches to these challenging cases. This is reflected in the NCEPOD and RCOphth recommendations and guidelines. ${ }^{1,2}$

We found that several respondents made particular comments regarding local difficulties, when units fail to discuss changes in out of hours arrangements, when a unit is forced to cease providing an out of hours service, as either an acute response to a staffing crisis or a permanent change in service provision. It is reasonable to expect that the neighbouring units, who will therefore be covering the service should be informed. ${ }^{8}$

Our results illustrate that the majority of ophthalmology departments hold a policy regarding the management of out of hours emergency cases that is in line with the Royal College of Ophthalmologists' guidelines, and with the observations of the NCEPOD report. The essence of these documents is that there should be 'few occasions' to operate after midnight, and that the majority of major emergencies should be performed within normal working hours when there is a higher level of skill and experience amongst all theatre professionals. Indeed, a significant proportion of units reported that they had no specialist ophthalmic nursing support during the out of hours period; this is not in line with the RCOphth guidelines. ${ }^{2}$

The decision to defer surgery to normal working hours is supported by recent research on delayed primary repair in patients injured in military conflict situations, where low complication rates were observed with this approach. ${ }^{4}$ The belief that delayed surgery would not significantly affect the outcome for the patient was a quoted reason for deferral for 183 responding consultants in our survey.

Delayed access to theatre is a common barrier to out of hours surgery; the recommendations of the NCEPOD report suggest strategies to avoid 'queuing' for theatre time. ${ }^{1}$ Related to problems with access, there was a small number of units which reported no or very poor anaesthetic cover for out of hours surgery.

Surgeon/staff fatigue was a concern, as was the belief that the quality of work performed out of hours was often inferior. In many surgical specialties, this has led to the institution of shift patterns of work by consultants for out of hours work. The low rate of surgical intervention associated with good planning of daytime surgical time has meant that this style of work has not become popular within ophthalmology.

The demands on the out of hours services in different ophthalmic units vary greatly with different population demographics. This means that absolute 
recommendations may be inappropriate but clear guidelines and an accumulating body of evidence will help to optimise out of hours working practices. This data set represents 'real-life', policies and practices of ophthalmologists who are exposed to the challenges of managing the emergency surgical case, and provides important information on this topic.

\section{Conclusion}

Organisation of available surgical resources and personnel is vital to the provision of optimal care, and this survey has provided useful data on how this is currently managed in United Kingdom.

\section{Summary}

\section{What was known before}

- The management of out of hours services has changed in recent years.

- The EWTD changes in specialist training and economic measures have had an impact on the availability of out of hours staff and facilities.

- There are national guidelines and an increasing body of published evidence regarding the management of emergency ophthalmic surgical cases out of hours.

\section{What this study adds}

- The majority of ophthalmology units have a time limit beyond which they are unlikely to bring a patient to theatre.

- A significant minority of units have no out of hours services, or no operating facilties or nursing support for their out of hours services.

- There are many different attitudes to the optimum management of the emergency surgical cases.

\section{Conflict of interest}

The authors declare no conflict of interest.

\section{Acknowledgements}

We thank Mrs Tracy Sparey for her help with the administration of this survey.

\section{References}

1 Cullinane M, Gray AJG, Hargreaves CMK, Lansdown M, Martin IC, Schuber M et al. The Report of the National Confidential Enquiry into Perioperative Deaths, 2003.

2 Briggs M. Emergency eye care. The Royal College of Ophthalmologists Ophthalmic Services Guidance 2009; www.rcophth.ac.uk.

3 Lowry J, Cripps J. Results of the online EWTD trainee survey. Ann R Coll Surg Engl 2005; 87(Suppl): 86-87.

4 Blanch RJ, Bindra MS, Jack AS, Scott RAH. Ophthalmic injuries in British armed forces in Iraq and Afghanistan. Eye 2011; 25: 218-223.

5 The Ocular Trauma Classification Group. A system for classifying mechanical injuries of the eye (globe). Am J Ophthalmol 1997; 123(6): 820-831.

6 Colyer MH, Weber ED, Weichel ED, Dick JS, Bower KS, Ward TP et al. Delayed intraocular foreign body removal without endophthalmitis during operations Iraqi Freedom and Enduring Freedom. Ophthalmology 2007; 114(8): 1439-1447.

7 Colyer MH, Chun DQ, Bower KS, Dick JS, Weichel ED. Perforating globe injuries during operation Iraqi Freedom. Ophthalmology 2008; 115(11): 2087-2093.

8 Jaques $\mathrm{H}$. Moving towards consultant delivered care. BMJ Careers. http://careers.bmj.com/careers/advice/ view-article.html?id=20005242. Accessed on November 2011. 